Copyright (C) 2017 by Academic Publishing House Researcher

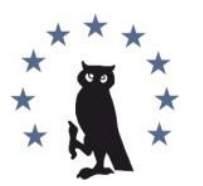

Published in the Russian Federation

European Researcher. Series A

Has been issued since 2010.

ISSN 2219-8229

E-ISSN 2224-0136

2017, 8(2): 93-97

DOI: 10.13187/er.2017.2.93

www.erjournal.ru

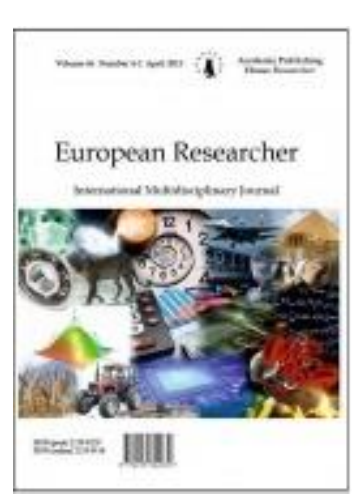

UDC 7.01

\title{
Perception within the Pictorial Activity
}

Lala Mammadova ${ }^{a}$,

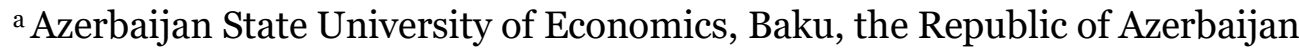

\begin{abstract}
The experience of perception plays particularly important role in the process of pictorial activity. Perception is the process reflecting objects and phenomena of reality in all the diversity of their properties and aspects affecting directly the sense organs.

In the context of the specificity of pictorial activity, the process of cognition of the spatial properties of the objects of reality is carried out, first of all, through visual and tactile perceptions.

Thus, the success of cognition of reality in the process of pictorial activity is determined by the artist's conscious activity aimed at revealing the surrounding world and reflecting it in artistic works, which, in turn, requires the knowledge of the general regularities of the perception process and their use in pictorial creativity.

Keywords: Perception, the process of perception of objects, the process of depiction, form and color, visual art, observation, cognition of reality, visual process

\section{Introduction}

The experience of perception plays particularly important role in the process of pictorial activity. Perception is the process reflecting objects and phenomena of reality in all the diversity of their properties and aspects affecting directly the sense organs.

Through perception a person acquires profound knowledge of the surrounding reality. Perception and sensation, being the parts of a single process of sense knowledge, the forms of reflection of reality, are inseparably connected to each other. At the same time, they have their own distinctive features. As a result of sensation, we get knowledge about the individual properties and qualities of the objects, and as a result of perception we get a holistic vision of an object or phenomenon.

Perception of the surrounding reality is the beginning of mental processes. Its significance in a structured learning system is determined by two factors. The first one is the most important role of perception in the organization of the practical activity of the object. It is appropriate at this point to recall the words of Sechenov I.M.: "Any rational action is regulated by feelings". The second factor, which found a brief description in the words of the English philosopher-sensualist John Locke "Nothing is in the intellect that was not first in the senses", is the formation of thinking on the basis of perceptual processes (Velichkoskiy et al., 1973: 5).
\end{abstract}

\footnotetext{
${ }^{*}$ Corresponding author

E-mail addresses: lala.mamedova1972@gmail.com (L. Mammadova)
} 


\section{Relevance}

In the process of perception, along with senses, the past experience is included in the form of knowledge and imagination. The process of cognition is possible due to grounding of perception on past experience, since without correlation of the perceived objects, phenomena, and their parts with previously seen objects, phenomena, and with no use of specific knowledge obtained in the past, we will not be able to define and comprehend the essence of the perceived one.

In the context of the specificity of pictorial activity, the process of cognition of the spatial properties of the objects of reality, their form, design, size, volume is carried out, first of all, through visual and tactile perceptions.

In the cognition of the spatial properties of objects, the leading role is played by the visualmotor functional system of perception during viewing. In the process of pictorial activity, the visual-motor functional system of perception is presented in two basic forms. The first one is characterized directly by the movement of the eyes and head. Due to the complex structure of the motor system of the eye, it can perform countless and very diverse movements.

Another form of the visual-motor functional system of perception is presented in the simultaneous perception of the image object, both through the eyesight and the movement of the hand. For more precise determination of the structure of the pictorial object, its proportions, shape, texture, surface, an artist often moves beyond the viewing, and starts to touch, turn in different directions, palm, etc.

For disclosure of the perception characteristics of the objects' spatial properties, we should consider the minimum cognoscible of the shape and the minimum discernible of the size of objects.

The minimum visual angle, within which the form of an object is first recognized, is called the minimum cognoscible of shape.

The ratio of the size of the perceived object to the distance of the observer is a parameter determining the visual angle. The larger the visual angle is, the greater the object image is on the amphiblestrodes (the eye's retina), and the better you see the object. The human eye cannot make out the small objects located very far away. Only as we approach them, i.e. as the visual angle increases, the eye first recognizes them as a dark point or spot of an undefined shape, and with a subsequent decrease in distance, as a clear, definite form of a particular object. At the moment when the shape of an object is recognized as a definite form of a particular object, the minimum cognoscible is reached. (Kuzin, 1997: 304).

The most insignificant differences in the shapes or outlines of objects, first noticed by the observer, are called the minimum discernible of the size of the object and the ratio of its parts. (Kuzin, 1997).

\section{Discussion}

By means of exercises, you can significantly reduce the thresholds of both perception and sensation. At the same time, the sensitivity increases, since it is the reciprocal of threshold. The effect is achieved due to the gradual reinforcement of one stimulus and at the same time slowdown of others, and thus a more subtle delimitation of similar stimuli is produced.

The results of determination of the minimum discernible of the proportions of planar figures show that, for example, the minimum discernible of the aspect ratio of a rectangle in artists is 45 times lower in comparison with a similar threshold of people who have nothing to do with pictorial activity (Kuzin, 1997).

The pictorial process develops the susceptibility of the eye to the maximum changes in size, direction, and shape so much that, as a rule, an experienced artist, making the smallest errors in the initial stages of the work, will notice and correct them certainly.

Great importance for the visual perception of the volume, the relief of the object has the distribution of light and shade on its surface. In fact, the object is visually perceived only when the light and shade reveal the shape and volume of the object.

The light and shade is a consequence of different positioning of the object and surfaces limiting it with regard to the light sources.

Since the surrounding objects really exist and there are real sources of light, we have certain objective laws of light and shade, the knowledge of which is necessary for the implementation of a realistic work, for the successful reproduction of the light and aerial environment, the variety of color reflexes and space in painting and graphics. 
Color and light are two tools creating a visually perceptible appearance of an object. The ability of the eye to make out different light and color spaces, defines the boundaries creating the outlines of the object. In the same way, the eye makes out lighting and darkening, which are important factors in creating a three-dimensional shape. An example is a graphic drawing, where the light and color differences between ink and paper make noticeable the image outlines. Roundness and angularity are perceived due to the fact that they are completely independent specific ratios of light and shadow (Arnkheym, 1974: 313).

Shape and color. "... Shape and color ... fulfill the two most characteristic functions of vision: they convey expression, and they allow us to obtain information through the identification of objects and happenings... Shape enables us to distinguish things from each other, but color also helps considerably. In signals, graphs, uniforms, color is used as a means of communication. Shape, however, is a more effective means of communication than color, on the other hand, the expressive impact of color cannot be obtained by shape. Shape yields and immense variety of clearly distinguishable patterns, as faces, leaves, and fingerprints" (Arnkheym, 1974: 313).

Perception is characterized by a number of regularities, the main of which are: integrity, meaningfulness, apperception, selectivity, constancy.

Any object, being a complex stimulus consisting of a number of parts and differing in various features, is perceived, however, entirely in the unity of all its qualities and features, causing the generality and integrity of perception.

A holistic perception of reality is the basic principle of fine art. The ability to see and express this integrity in the work is one of the main and final goals in the pictorial activity. Integrity of visual perception is necessary for any realistic image, ranging from a minute life sketch to a complete work - a picture, a sculpture, etc.

Usually the components of the complex stimulus interact so closely that even with the perception of only certain features or parts of the object, the whole image of this object appears. Visually perceiving, for example, velvet, we distinguish not only its color, but also softness, although we do not touch it.

Such feelings arise conditionally, as a result of the association established and ingrained in the previous practice between the visual, tactile, and temperature stimuli from these objects.

An association of visual, motor and tactile sensations happens quickly and easily. Perceiving the shape of objects or their individual surface properties-smoothness, roughness, flatness, etc., we notice such a close fusion of these sensations that it is impossible to distinguish them in a single complex of sensations.

During reproduction of the objects of reality in the visual arts, along with others, this regularity is also taken into account. If, for example, the artist, while representing a particular object, along with the correct reproduction of the spatial position, construction, proportions of the object in the drawing, failed to convey the material, texture (density, smoothness, roughness, etc.), then there is a violation of associations of different sensations. As a result, the integrity of perception is not observed, i.e. the image does not give a complete, unified view of the depicted object. (Stepanov, Borisova, 2015: 106-107).

Sense of purpose is a characteristic feature of any person's perception. From the very beginning of the perception process of the objects and phenomena of reality, person seeks to determine what it is or how it will be in this subject, etc., based on his/her knowledge and practical experience. The sense of purpose of perception is achieved through understanding the meaning of objects and phenomena, that is, through the mental activity of a person in the process of perception.

In the pictorial process, perception is almost always distinguished by an independent activity. This independence of perception is especially clear in observation.

Observation is the purposeful perception.

The pictorial process is not possible without the concreteness and definiteness of the purpose of perception, therefore the success of the image is connected with the organization of observation.

Being characterized by a special orientation and the presence of a goal, the observation is an active form of sensory cognition by a person of the world around.

In the process of drawing the artist always sets specific tasks before the observation of nature. And the accuracy of the image, which is necessary for a true, expressive reproduction of the image 
object, requires close and focused observation of this object in all its aspects, which determines the development of observance in artists.

Observation of the artist determines the active participation of mental operations in the process of drawing, and above all in the process of comparison, generalization, analysis and synthesis.

Specificity of pictorial creativity requires the artist to accumulate a wealth of impressions, a variety of observations. To accumulate impressions, artists, wherever they are, should constantly observe, notice many things and phenomena that are imperceptible at first sight. So, gradually, observation becomes an integral feature of the artist's personality.

"Seeing means grasping some outstanding features of objects - the blueness of the sky, the curve of the swan's neck, the rectangularity of the book, the sheen of a piece of metal... We identify an acquaintance at long distance by nothing more than the most elementary proportions or motions. A crudely printed photograph may reduce a face to dots or varying grays and still allow spontaneous recognition. In short, a few outstanding features determine the identity of the perceived object and create an integrated pattern, which is also influenced by a number of secondary properties" (Arnkheym, 1974: 56).

Considering the general regularities of the process of perception and their significance in the pictorial activity, it is first of all necessary to single out in this connection the process of performing work from life. Performing work from life, the artist more fully and deeply learns the surrounding reality, since in this case the object of the image is the subject, which in the process of direct sensation, perception and thought, thanks to the active work, is comprehensively understood. The image from life requires active inclusion in the process of learning, knowledge of the nature of all parts of a single cognition process - sensation, perception, and thinking. This is the special meaning of the reproduction from life as the main, leading type of pictorial activity in the study of objects of the image, in the knowledge of the surrounding reality. It is not for nothing that from the earliest times artists see the work from life as the basis of fine art.

All outstanding works of the world fine arts are created on the basis of a deep and comprehensive study of nature in drawings and sketches.

A distinctive feature of visual perception in the process of systematic studies of visual arts is the perception, first of all, of those features and regularities of the depicted objects with the greatest aesthetic impact.

The knowledge of the aesthetic in perceived objects and phenomena is impossible without the knowledge of what determines the beauty of a particular object. And it is no coincidence that an experienced teacher of fine arts, a professional artist, even in the selection of objects for a still life paintings, proceeds from the way the objects of still life are relevant to each other in form, size, contone contrast, color, the way they are assembled, whether they look harmoniously and proportionally, the presence of monotony in the repetition of lines, forms, colors, black and white relations.

The task of the development of aesthetic perception, emotional-aesthetic sense of the correlation of certain forms, their spatial arrangement, outlines, proportions, combination of tonal and color gradations are many training tasks and exercises in the system of professional training of painters, graphic artists, designers, etc.

\section{Conclusion}

Thus, we can conclude that, the success of cognition of reality in the process of pictorial activity is determined by the artist's conscious activity aimed at revealing the surrounding world and reflecting it in artistic works, which, in turn, requires the knowledge of the general regularities of the perception process and their use in pictorial creativity.

\section{References}

Velichkoskiy, Zinchenko, Luriya, 1973 - Velichkoskiy B.M., Zinchenko V.P., Luriya A.R. (1973). Psychology of perception, Publishing house of Moscow University, 5 p.

Arnkheym, 1974 - Arnkheym R. (1974). Art and visual perception, Publishing House «Progress», Moscow, p. 56.

Kuzin, 1997 - Kuzin V.S. (1997). Psychology, textbook, 3rd p. M.AGAR, 304 p.

Bichkov, 2002 - Bichkov V.V. (2002). Aesthetics, Moscow, 298-307. 
Stepanov, Borisova, 2015 - Stepanov V.G., Borisova A.I. (2015). Visual perception and visual arts, Pedagogy and psychology of education, 4, 106-107.

Yung, 1987 - Yung K. (1987). On the relationship of analytical psychology to poetic-artistic creativity, Foreign Aesthetics and Literature Theory, Moscow, 230 p.

Berdyayev, 1989 - Berdyayev N.A. (1989). Sense of creativity, Moscow, 347 p.

Tugusheva, 2006 - Tugusheva R.Kh. (2006). General Psychology (Educational Standard XXI).

Tikhomirov, 1975 - Tikhomirov O.K. (1975). Psychological research of creative activity, Moscow, Nauka, 253p.

Ponamaryev, 1976 - Ponamaryev Y.A. (1976). Psychology of creativity, Moscow, Publishing House Nauka. 